\title{
Chikungunya Fever: An Emerging Threat to Bangladesh
}

\author{
FAIJUL ISLAM CHOWDHURY, ${ }^{1}$ AHMEDUL KABIR, ${ }^{2}$ APARNA DAS, ${ }^{3}$ SHEGUFTA MISHKET MUKERRAMA,${ }^{4}$ SHAHIN MASUD $^{5}$
}

\section{Introduction:}

Chikungunya fever is a relatively rare form of viral fever caused by an alpha virus that is spread by bite of Aedes aegypti mosquito. The name is derived from the Mekonde word meaning 'that which contorts or bends up' in reference to the stopped posture developed as a result of the arthritic symptoms of the disease. From the serum of a febrile human in Tanganyika (Tanzania) in 1953, Chikungunya was first isolated. Between the 1960s \& 1980s the virus was isolated repeatedly from numerous countries in Central \& Southern Africa, in Senegal \& Nigeria in Western Africa including Zimbabwe, Zambia \& Congo. During this same period, the virus was also identified in many areas of Asia including India, Sri Lanka, Thailand \& Vietnam.

\section{Aetiology:}

Chikungunya virus or CHIK virus is a Group IV (+) RNA virus belonging to family Togaviridae with Genus Alphavirus and species Cikungunya virus. ${ }^{1}$

\section{Structure of Chikungunya virus:}

The complete genome sequences of the Chikungunya virus have been identified from viral isolates obtained from a low number of cell culture passages. The structure has a diameter of about $50 \mathrm{~nm}$ to $70 \mathrm{~nm} .{ }^{2}$ Chikungunya virus consists of a single stranded positive sense RNA. ${ }^{3}$ The "molecular signatures "of Chikungunya virus, which constitute genetic fingerprints, in virus envelope protein E1 have also been found. ${ }^{4}$ The scientists suggest that, this signature may confer an advantage and favour the multiplication of the virus in Aedes albopictus, its vector (protein E1 is in fact involved in attaching the virus to the mosquito's cell membranes).

\section{Transmission:}

Chikungunya virus is most commonly transmitted to humans through the bite of an infected mosquito, specifically mosquitoes of the Aedes genus, usually by Aedes aegyptiwhich usually bite during daylight hours. ${ }^{5}$ In Africa, the vector involved in forest area is Aedes africanus \& in Sudan the vector is Aedes luteocephalus. Various Culex species are also involved in urban epidemics in Asia.

\section{Epidemiology:}

In Africa, Chikungunya virus is transmitted in the savannah $\&$ forests of tropical Africa by Aedes mosquito \& the vertebrate portion of the cycle is provided by non-human primates such as monkeys or baboons which amplify \& maintain virus circulation. ${ }^{6}$ In African villages or rural areas these mosquitoes may then infect humans \& the substantial viraemia measure suggest that humans, in appropriate setting may contribute to mosquito infection, leading to further virus amplification.

Transmission in Asia follows a different pattern from that scene in Africa, being primarily transmitted from human to human by Aedes aegypti \& the human epidemics have all been in urban areas infested with Aedes mosquito. CHIK activity in Asia has been documented since its isolation in Bangkok, Thailand in 1958. A series of epidemics usually lasting a single year have been reported from Sri Lanka \& Philippines.

\section{Reasons for re-emergence of Chikungunya infection:}

- Absence of herd immunity- susceptible population.

- Viral mutation.

- Increased air travel, tourism.

- Virus never disappeared, simple resurgence.

\section{Current scenario in Bangladesh:}

Recently an outbreak of Chikungunya fever has been discovered in Dhaka, Dohar \& Nababganj of Dhaka district \& also in Shibganj of Chapainababganj. According to IEDCR, 250 samples have been collected, among them the virus has been identified in the body of 46 persons. According to the information of Prothom Alo on $24^{\text {th }}$ November, this is the $3^{\text {rd }}$ outbreak in Bangladesh. The $1^{\text {st }}$ one was in Poba upozilla in Rajshahi district affecting 32 people in 2008. The $2^{\text {nd }}$ outbreak was in Shathiya upazilla of Pabna in 2009.

1. Associate Professor, Department of Medicine, Dhaka Medical College, Dhaka.

2. Assistant Professor, Department of Medicine, Dhaka Medical College, Dhaka.

3. Assistant Professor, Department of Medicine, Dhaka Medical College, Dhaka.

4. Medical Officer, Department of Medicine, Dhaka Medical College, Dhaka.

5. Assistant Registrar, Department of Medicine, Dhaka Medical College, Dhaka.

Correspondence : Dr. Faijul Islam Chowdhury, Associate Professor, Department of Medicine, Dhaka Medical College, Dhaka. 


\section{Natural history of disease:}

This disease is biphasic:

$\mathbf{1}^{\text {st }}$ phase: It consists of fever \& severe joint, limb \& spine pains. Myalgia \& conjunctivitis may also be present. It may last for 6-10 days.

$2^{\text {nd }}$ phase: It begins after a febrile period of 2-3 days \& is associated with an irritating maculo-papular rash over the body, particularly on extensor surface of the limbs. Joint pain may persist occasionally without fever, for up to 4 months. Petechiae, bleeding from gums \& a positive tourniquet test have been seen in many patients \& may lead to the infection being mistaken for dengue. ${ }^{7}$

In some cases, myocarditis \& peripheral circulatory failure have been seen. Encephalitis \& menifestations of neurological involvements are occasionally observed. Some patients may develop a febrile illness without a rash or arthralgia. Most patients recover fully over a few weeks, although 5-10\% experience chronic joint symptoms including pain, stiffness \& swelling that may persist for years. ${ }^{8}$ The ESR is often mildly elevated in acute \& chronic cases. Children who are infected are less likely to develop chronic illness.

Mortality rate is estimated at $0.4 \%$ but in patients aged under one year, it is as high as $2.8 \% \&$ similarly in those aged more than 50 years, death rate increases.

Incubation period: It is usually 2-3 days, with a range of 1-12 days.

\section{Clinical Features:}

Chikungunya is an acute infection of abrupt onset, characterized by fever \& arthralgia, followed by other constitutional symptoms and rash \& lasting for a period of one to seven days.

1) Fever: fever rises abruptly often reaching 39 to 40 degree centigrade $\&$ accompanied by intermittent shaking chills. This acute phase lasts two to three days. The temperature may remit for one to two days, resulting in a 'saddle-back' fever curve.

2) Arthralgia : The arthralgias are polyarticular, migratory \& predominantly affect the small joints of hands, wrist, ankles \& feet with lesser involvement of larger joints.

Pain on movement is worse in the morning improved by mild exercise \& exacerbated by strenuous exercise. Swelling may occur but fluid accumulation is uncommon. Arthralgia usually accompanied by myalgia $\&$ fatigue. Tendonitis $\&$ fascitis may also be clinically evident. Patients with milder articular menifestations are usually symptom free within a few weeks, but more severe cases require months to resolve entirely \& may lead to crippling arthritis. Generalized myalgias as well as back \& shoulder pain is common.
Chronic joint pains are seen in about 1 in 10 cases of Chikungunya infection. The persistant joint pain may be mistaken for rheumatoid arthritis.

3) Cutaneous manifestation: They are typical with many patients presenting with a flush over the face \& trunk, usually followed by a rash generally described as maculo-papular. ${ }^{9}$ Sometimes rashes are accompanied by severe itching. In many cases rash marks last for a long time (especially the ones on the face). The trunks \& limbs are commonly involved but face, palms \& soles may also show lesions.

4) During the acute disease, most patients will have headache.

5) Photophobia \& retro-orbital pain may also occur but not severe.

6) Conjunctival infection is present in some cases.

7) Although rare, the infection can result in meningoencephalitis especially in newborns \& those with preexisting medical conditions.

8) In pregnant woman the biggest risk is the possibility of transfer of virus to the foetus. In addition, delivery becomes complicated if the infection starts late in the pregnancy sometimes requiring caesarean section. The virus is not transmitted through the breast milk.

9) Chikungunya can be deadly in the case of very old and in newborns. Patients with poor immune systems may require hospitalization.

\section{Case definition:}

- Suspect case: An acute illness characterized by sudden symptoms of fever with several of the following symptomsjoint pain, headache, back ache. Photophobia, arthralgia \& rash.

- Probable case: As above \& positive serology (when single serum sample is obtained during acute phase or during the convalescence).

- Confirmed case : A probable case with any of the following:

1) Four fold $\mathrm{HI}$ antibody difference in the paired serum sample.

2) Detection of IgM antibody.

3) Virus isolation from serum.

4) Detection of Chikungunya with virus Nucleic acid in sera by RT-PCR.

\section{WHO criteria for Chikungunya diagnosis:}

- Clinical criteria: acute onset of fever $>38.5^{\circ} \mathrm{C}$ and severe arthralgia/arthritis not explained by other medical conditions.

- Epidemiological criteria: residing or having visited epidemic areas, having reported transmission within 15 days prior to the onset of symptoms.

- Laboratory criteria: at least one of the tests mentioned above. 
Difference between Dengue \& Chikungunya: Dengue

\begin{tabular}{|c|c|c|}
\hline Aspect & Dengue & Chikungunya \\
\hline Clinical features & $\begin{array}{l}\text { Fever, headache, joint pains (Break-bone fever), } \\
\text { retro- orbital pain, lower back pain are the usual } \\
\text { features. }\end{array}$ & $\begin{array}{l}\text { Fever, joint pains, myalgia, conjunctivitis and } \\
\text { maculo-papular rash are the usual features } \\
\text {. }\end{array}$ \\
\hline Course & $\begin{array}{l}\text { In Dengue fever patient apparently improves } \\
\text { after } 3 \text { to } 4 \text { days, around } 5^{\text {th }} \text { to } 6^{\text {th }} \text { day fever } \\
\text { intensifies and the patients' conditions } \\
\text { can rapidly deteriorate. }\end{array}$ & $\begin{array}{l}\text { The course is of benign disease which usually } \\
\text { heals spontaneously after } 1 \text { week }\end{array}$ \\
\hline Chronicity & There is no chronicity. & $\begin{array}{l}\text { There may be chronicity, the disease may } \\
\text { last for week to months. }\end{array}$ \\
\hline Subsequent Attack & $\begin{array}{l}\text { Patient with Dengue are always in risk of } \\
\text { subsequent attack by a different serotype } \\
\text { of dengue virus. }\end{array}$ & $\begin{array}{l}\text { Once an attack of Chikungunia gives } \\
\text { lifelong immunity. }\end{array}$ \\
\hline Complication & $\begin{array}{l}\text { It may become fatal. With life threatening } \\
\text { bleeding, patient may present with shock. }\end{array}$ & $\begin{array}{l}\text { It is usually non fatal, temporary meningo- } \\
\text { encephalitis in young children and new born } \\
\text { babies may occur rarely. }\end{array}$ \\
\hline Treatment & $\begin{array}{l}\text { Classical Dengue fever needs supportive } \\
\text { treatment. Fever can be treated with } \\
\text { paracetamol. DHF and DSS need good medical } \\
\text { care and patient should be treated with right } \\
\text { amount of I.V. fluid. }\end{array}$ & $\begin{array}{l}\text { Purely symptomatic treatment with paracetamol } \\
\text { or NSAID. }\end{array}$ \\
\hline
\end{tabular}

The clinical menifestations of Chikungunya fever resemble those of Dengue fever, laboratory diagnosis is critical to establish the cause of disease \& initiate specific public health response.

Three main laboratory tests are used for diagnosing Chikungunya fever:

- Virus isolation.

- Serological tests.

- Molecular diagnosis by Polymerase Chain Reaction.

Collection of samples for serology:

- Sample: Blood in plain vial/serum.

- Time of collection:

$1^{\text {st }}$ sample: Five days after onset of illness for IgM detection as these antibodies appear at this time.

$2^{\text {nd }}$ sample: At least 7-10 days after the $1^{\text {st }}$ sample.

Collection of samples for Isolation \& Molecular diagnosis:

- Sample: Serum.

Mosquitoes collected in nature.

- Time of collection: Within first 5 days of illness.

\section{Laboratory tests:}

1) Virus isolation: It is the most definitive test. Chikungunya virus produces cytopathic effects in a variety of cell lines including BHK-21, HeLa \& Vero cells. The cytopathic effects must be confirmed by CHIK specific antiserum $\&$ the results can take between one to two weeks.

2) RT-PCR: Recently, a reverse transcriptase, RT-PCR ${ }^{10}$ technique for diagnosing Chikungunya virus has been developed using nested primer pairs amplifying specific components of three structural gene regions- capsid(C), Envelope E2 \& part of Envelope E1. PCR results can be available from within one to two days.

3) Serological diagnosis: It can be made by demonstration of fourfold increase in antibody in acute \& convalescent sera or demonstrating IgM antibodies specific for Chikungunya virus.

A commonly used test is the Immunogloulin M antibody (IgM) capture enzyme linked immunosorbent assay (MACELISA). ${ }^{11}$ Results of MAC-ELISA can be available within one day.

\section{Interpretations of results:}

- Sero-diagnosis tests on demonstrating a fourfold increase in CHIK IgG titer between the aute \& convalescent phase sera. However, getting paired sera is usually not practical. Alternatively, the demonstration of IgM antiodies specific 
for Chikungunya virus in acute phase sera is used in instances where paired sera cannot be collected.

- A positive virus culture supplemented with neutralization is taken as definitive proof for the presence of Chikungunya virus.

- PCR results for E1 \& C genome either singly or together constitute a positive result for Chikungunya virus.

\section{Treatment:}

- There is no specific treatment for Chikungunya. The illness is usually self-limiting \& will resolve with time.

- Main purpose of treatment is the management of fever and pain. For treatment of Chikungunya fever, Paracetamol is given in the first few days. It is only required in cases where fever management is essential.

- Other medical conditions if any must be evaluated before taking any medicines. Other non steroidal medicines such as Tramadol may be taken for pain management.

- Non-aspirin \& non-steroidal anti inflammatory drugs are recommended. There is no role of antibiotics \& antiviral agents. $^{12}$

- Supportive care with rest is indicated during acute joint symptoms. Movement \& mild exercise tend to improve stiffness \& morning arthralgia, but heavy exercise may exacerbate rheumatic symptoms.

- It is important to maintain a healthy life style to promote early recovery from Chikungunya joint pain. A healthy diet which includes fruits and vegetables and good sleep promotes early recovery.

- In unresolved arthritis refractory to NSAID, Chloroquine ${ }^{13}$ is found to be effective.

\section{Prognosis:}

- Chikungunya is rarely fatal. Recovery from the disease varies by age. Younger patients recover within 5 to 15 days; middle-aged patients recover in 1 to 2.5 months. Recovery is longer for the elderly.

- However, the chronic joint pain associated with it can substantially reduce the quality of life for a patient.

\section{Vaccine against Chikungunya:}

- Currently there are no vaccines available in the market for preventing Chikungunya disease. ${ }^{14,15}$

- However scientists have developed a working vaccine for Chikungunya. The experimental Chikungunya vaccine contains noninfectious virus like particles coated with the same protein that enables Chikungunya virus to pass through cell walls.
- However the vaccine particle doesn't contain the proteins that Chikungunya uses for replication and hence is harmless.

- The vaccine looks like Chikungunya virus to the immune system which in turn produces antibodies against it. From the experiments on monkeys it was found that these antibodies can prevent Chikungunya infection.

- Monkeys were injected with the vaccine and then after 15 weeks they were injected with Chikungunya virus. It was found that the vaccine offered $100 \%$ protection from the disease. The next step for this vaccine is human testing.

- In the case of Chikungunya, careful evaluation is required before any vaccination is recommended.

- Chikungunya is relatively a low risk infection and hence vaccine side effects must be compared with the actual risk for Chikungunya infection.

- Obviously in areas where the infection incidence is low and where mosquitoe bites are also low, probably there is no need for a vaccine. So when the Chikungunya vaccine becomes available, it is up to the individuals to take an informed decision.

\section{Prevention \& Control:}

- There is no vaccine or specific medication available against Chikungunya infection.

- Vector control is thus very important in controlling or preventing Chikungunya transmission. Elimination of breeding sites or source reduction is an effective method of control. Aedes aegypti is typically a container habitat species \& breeds primarily in artificial container \& receptacles.

- The best way is to encourage people to eliminate the mosquito habitats by emptying water containers once a week \& keeping the permanent water containers covered with a tight fitting lid. Adoption of these methods can be encouraged through community based programmes.

- Legislation, strong public advocacy \& community involvement can also help in vector control.

- Personal protection like long sleeve clothes, covering oneself fully, use of repellents, window nets play limited but useful role.

- Use of standard case mangement guidelines help in reducing the mortality due to Chikungunya.

Conflict of Interest : None 


\section{References:}

1. Peters, CJ, Dalrymple, JM. Alphaviruses. In: Fields BN, Knipe DM, Chanok RM, editors. Virology, $2^{\text {nd }}$ edition. New York: Raven Press. 1990. 713-761.

2. Simizu B, Yamamoto K, Hashimoto K, Ogata T. Structural proteins of Chikungunya virus. J Virol 1984; 51: 254-258.

3. Higashi N, Matsumoto A, Tabata K, Nagatomo Y. Electron microscope Study of development of Chiukungunya virus in green monkey kidney stable (VERO) cells. Virology 1967; 33: 55-69.

4. Strauss JH \& Strauss EG. The alphaviruses: gene expression, replication and evolution. Microbiol Rev 1994; 58: 491562.

5. Tsetsarkin KA, Vanlandingham DL, McGee CE, Higgs $\mathrm{S}$ (2007)A single mutation in Chikungunya virus affects vector specificity and epidemic potential. PLoS Pathog 2007; 3: e201.

6. Peyrefitte CN, Bessaud M, Pastorino BAM, Gravier P, Plumet S, et al. Circulation of Chikungunya virus in Gabon. 2006-2007. J Med Virol 2008; 80: 430-433.

7. Brighton A W, Prozesky O W \& De La Harpe HD. Chikungunya virus infection. A retrospective study of 107 cases. S. Afr Med J 1983; 63: 313-315.

8. Nimmannitya S, Halstead S B, Cohen S N et al. Dengue \& Chikungunya virus infections in man in Thailand, 1962-1964.
I) Observations on hospitalized patients with haemorrhagic fevers. Am J. Trop Med Hyg 1969; 18:954- 971 .

9. Halstead S B, Nimmannitya S \& Margiotta M R. Dengue \& Chikungunya virus infections in man in Thailand, 19621964. II) Observations on dengue in outpatients. Am J. Trop Med Hyg 1969; 18: 972-983.

10. Parola P, De Lamballerie X, Jourdan J, Rovery C, Vaillant V, Minodier P. Broqui P, Flahault A, Raolutt D, Charrel RN. Novel chikungunya virus variant in travelers returning from Indian ocean islands. Emerg Infect Dis 2006; 12: 1493-1498.

11. Sam IC and Abu Bakar S . Chikungunya virus infecion. Med J Malaysia 2006; 61: 264-269.

12. Tesh RB. Arthritides caused by mosquito-borne viruses. Annu Rev Med 1982; 33: 31-40.

13. Brighton SW. Chloroquine phosphate treatment of chronic chikungunya arthritis. An open pilot study. S Afr Med J 1984; 66: 217-218.

14. Edelman R, Tacket CO, Wasserman SS, Bodison SA, Perry JG, Mangiafico JA. Phase II safety \& immunogenicity study of live chikungunya virus vaccine TSI-GSD-218. AM J Trop Med Hyg 2000; 62: 681-685.

15. Levitt NH, Ramsburg HH, Hasty SE, Repik PM, Cole FE, Lupton HW 1986. Development of an attenuated strain of Chikungunya virus for use in vaccine production. Vaccine 1986; 4: 157-162. 